\title{
JOSÉ LUIS PARDO (2016): : Estudios del malestar. Políticas de la autenticidad en las sociedades contemporáneas. Barcelona: Editorial Anagrama, 296 pp.
}

El profesor José Luis Pardo examina en sus Estudios del malestar (2016) la sentimentalización de la política que están experimentando las democracias occidentales en la segunda década del siglo XX. Se trata de un análisis que entiende tal sentimentalización desde una óptica romántica, estética, y de ahí que el libro plantee un paralelismo entre la historia de la política y la de las "bellas artes", desde el siglo XIX hasta la actualidad. Este enfoque se justifica por cuanto ambas historias se interpretan -y critican- desde una misma matriz filosófica, inaugurada por G.W.F. Hegel y consolidada con el comunismo, que se arrogaría la garantía de la "autenticidad". Hablamos de esa visión teleológica que, desestimando la distinción aristotélica, incorpora carga de sentido al devenir humano e introduce el alcance universal de la poesía al desarrollo de la Historia, ahora con mayúscula.

Como explica Pardo, fue Hegel quien supeditó los hechos históricos a la trama (o "astucia") de la razón, poniendo "al tiempo en conceptos" (p. 30). Y avalando, en consecuencia, el papel de la guerra como instrumento histórico privilegiado, aquel que reduce al mínimo los "costes" del sentido. De acuerdo con el mismo esquema, Marx apuntaló el sello de autentificación filosófica, a través de la célebre $11^{\text {a }}$ Tesis sobre Feuerbach: "Los filósofos no han hecho más que interpretar el mundo, de lo que se trata es de transformarlo". El salto, que llevaba aparejado la legitimación de la única y última guerra justa (la lucha de clases), suponía a su vez la anunciación del fin de la filosofía, una invitación -como señala el autor- al suicidio de la disciplina, que se diluiría tras el triunfo de la revolución en la vida de la humanidad. Pero disuelta o no, en Marx seguía manteniendo su estatuto de doctrina verdadera, siempre por supuesto que equivaliese al comunismo. Y así, por más que sus argumentos sean más pasionales que racionales, lo sostienen todavía hoy los defensores de la Idea del comunismo (A. Badiou), en tanto pretendida clave de nuestra emancipación y última ratio de todo discurso crítico. Volveremos sobre esto más adelante.

De momento, reténgase la diferencia planteada entre un tipo de pensamiento "auténtico" y otro "inauténtico", activado en el trasfondo mental de quienes otorgan sentido a la Historia. Va de suyo que ello se refleja tanto en el plano político como en el estético. En el primero 
de ellos, el indicador principal de la inautenticidad radicaría en la asunción del gobierno de las leyes. Auténtica, por el contrario, sería la "acción directa" de los movimientos obreros decimonónicos que recurrían a la violencia y no aceptaban la mediación del parlamento, la idea de representación. Auténtica es la teoría de la sublevación en Foucault, expuesta como una disposición a morir antes que a obedecer, límite genuino al concepto real de poder pues rompe la médula de su lógica. Una facultad, por cierto, al alcance de cualquiera -una vez la guerra quedó democratizada por la lucha de clases- y que se sitúa por encima de toda ley. Auténtica (o realista) es en fin la concepción "conflictivista" de la política y falsa (o idealista) es la "contractualista", así como la noción de una paz desconectada de la guerra. Recuérdese a Foucault parafraseando a Clausewitz: "la política es la continuación de la guerra por otros medios".

En este punto merece la pena detenerse en la reflexión que Pardo reserva a Carl Schmitt, conflictivista filonazi académicamente rescatado, acaso por su calidad de jurista y delator de la "farsa" del Estado de derecho. Un análisis tanto más sugerente en cotejo con la obra de Th. Hobbes, fundador y máximo exponente del contractualismo. Veámoslo. La tesis de Schmitt arranca de dos premisas fundamentales: la esencia de "lo político" responde a la distinción entre amigos y enemigos y la base de la soberanía se cifra en el estado de excepción. Dicho de otro modo: la guerra y la decisiones al margen de la ley perfilan la naturaleza nuclear de lo político, un terreno al cabo en el que siempre está en juego nuestra propia existencia. Por descontado, es preciso introducir matices: las decisiones pueden generar normas y toda norma necesita, aun por simple automatismo, de decisión. El problema, a juicio de Pardo, consiste no obstante en la liquidación de la distancia entre norma y decisión.

Con todo, la mejor ilustración de las insuficiencias del decisionismo se revelaría en contraste con las propuestas de Hobbes, a partir precisamente del estudio que le dedicó Schmitt. Es entonces cuando queda nítidamente contrapuesta la perspectiva racional del inglés, frente a la perspectiva histórica del alemán, que condena la ficción teórica del "pacto social" y el olvido de los precedentes jurídicomedievales. A diferencia de Schmitt, Hobbes ciertamente se figuró una ficción, jamás documentada. Y sin embargo -diríase que haciendo de la necesidad virtud- lo hizo para dar respuesta cabal a la situación histórica que vivió, un momento fundacional que ve nacer una realidad política inédita, la de un Estado articulado ya no sobre prerrogativas divinas o dinásticas, sino sobre leyes públicas, vale decir: universalizables. Y así como, de acuerdo con Pardo (pp. 187-ss.), I. Kant se remontó al examen sobre las condiciones de posibilidad de la física newtoniana para reformular la cartografía del pensamiento filosófico, Hobbes habría procedido de manera análoga. E imaginó por tanto, en aras de redefinir el pensamiento político, unas condiciones de posibilidad antropológicas que abstrajeran todos los atributos sociales, económicos e históricos de los individuos, a excepción de su mero raciocinio. La figuración, por lo demás, no se encontraría en el "estado de naturaleza", plenamente coincidente con la excepcionalidad schmittiana $\mathrm{y}$, dicho sea de paso, "quintaesencia misma de la normalidad" (p. 192). En su lugar, estribaría en esa suerte de pacto a todas luces irreal, "firmado" por unos individuos sin más amigos que la ley que han contribuido a promulgar: un contrato ficticio, pero de claras consecuencias prácticas, en cuanto fija la génesis moderna de la legitimidad, afianza un 
corte "cualitativo" entre la guerra y la paz y, por ende, asienta la diferencia entre lo público y lo privado, toda vez que no hay privacidad sin que nos la asegure la ley.

Aquí viene al caso la referencia al Gorgias de Platón, en el que con siglos de antelación a Kant, Sócrates apeló al uso de leyes públicas dialógicas -que prohíbe las contradicciones y se abre a la rectificación- en detrimento de un empleo atento en exclusiva a la victoria dialéctica, cuando no al juego de sobreentendidos "en comandita", "entre amigos", el mismo que los "realistas" utilizarían al hablar de la embuste del contrato social. No obstante, el conflictivismo permanece a la orden del día.

Antes de explicar las razones aducidas, se hace ahora imprescindible retomar ese otro plano, estético, en el que siguiendo a Pardo se reproduce el dualismo entre el pensamiento auténtico y el inauténtico, desprendido de la filosofía de la historia de cuño hegeliano. Y ello en tanto las vanguardias artísticas plantearon a principios del siglo XX un desafío sobre su propia esfera equivalente al que propició el comunismo, a través de obras -el paradigma es La Fuente de Duchamp- que no es que no quisieran ser Arte, es que querían superarlo (aunque no se ignora el componente existencial, de vínculo con lo sagrado, que desde el romanticismo se atribuye el artista auténtico). En ese sentido, las vanguardias incitaban igualmente al fin o suicidio de la estética -por su absorción en la vida-, aniquilando toda distancia estética y erradicando como sucedía en la arena política la idea representación. $\mathrm{Y}$ he aquí de hecho su concomitancia con los totalitarismos, ligada a un ímpetu revolucionario que, al revés de lo que sucedió en política, se prolongó tras la II Guerra Mundial.

Entramos entonces, como subraya
Pardo, en un periodo de "déficit" de sentido, por cuanto la justificación racionalista de la guerra entró en declive, al tiempo que se consolidaron en Europa los Estados del bienestar, tratados de "paz social", que los filósofos auténticos interpretaron en términos de patraña, denunciado el entretenimiento narcótico de una paz embustera, de un bienestar a lo sumo jurídico (ideal), que no material, económico -real. Esta fase, se insiste, no implicó en todo caso un apaciguamiento artístico, dando en cambio lugar a una corriente postvanguardista empeñada en la misma misión suicida que las de sus antecesores, solo que ya "institucionalizada". Se produjo, y en esas continuaríamos, una especie de paralización de la Historia, en espera de que el porvenir adelantado por la vanguardia, de momento fallido, advenga. Mientras tanto, sumidos en la derrota de tener que circunscribir sus "intervenciones" en centros de arte contemporáneos ("instituciones antiinstitucionales", p. 274), los artistas genuinos andarían todavía a la espera de la llegada del pueblo auténtico que legitime su visión, aun conjurándolo en la estela engagé mediante obras políticocríticas que convergen con los objetivos de la "izquierda auténtica".

$Y$ es que, tras el lapso bienestarista, la caída del referente empírico (desviado) de la Idea comunista y los atentados del 11S, habría rebrotado la pulsión por el sentido histórico, en una Historia ahora "global", vivida desde el presente, en la que la paz y la guerra se vuelven indistinguibles y la poesía se transmuta en espectáculo. Pero como ya no sería posible recuperar el espíritu racional de la desacreditada filosofía hegeliana, su trama -como advertíamos al inicio- en vez de a razones, acude al único aspecto superviviente de la doctrina finalista: el sentimiento. A esto es a lo que Pardo, afrontando el tramo final del libro llama con W. Benjamin "estetización 
de la política", evocando el bagaje psicoanalista -que actualiza su carga libidinal en G. Deleuze- pero que de hecho no habría cuajado en un discurso ideológico hasta la propuesta populista de Ernesto Laclau.

$\mathrm{Su}$ fórmula, según la expone el autor, combina la concepción ontológica de Schmitt y la perspectiva estratégica de Gramsci -conectados por su común pensamiento conflictivista-, y se estructura a partir de la oposición entre amigos y enemigos y la conquista de la hegemonía, "palabra que por mucho que provenga de Gramsci no deja de significar "dominación"” (p. 262). Ahora bien, el quid del asunto radicaría en apreciar la insustancialidad de la realidad social postulada: ni hay enemigos sólidos (capitalismo, Estado burgués, etc.) ni hay amigos preexistentes (hay que fabricarlos, integrando demandas heterogéneas), dada la arbitrariedad desde la que aquella funda: un sistema lingüístico en el que los significantes cambian de significado a gusto de cada cual. De ahí la importancia de que "los amigos" logren la hegemonía, fundiéndose en el "todo" popular, a fin de dominar el lenguaje y, en consecuencia, la sociedad. A tenor de lo antedicho, la falla consistiría en la ausencia de unas reglas públicas, en favor de una simbología voluble -"flotante", en la terminología de Laclau- que, aun inclinada hacia la Idea comunista, conduciría por fuerza a un estado de permanente tensión, de antagonismo recurrente -de malestar. Se trata en suma de la misma guerra dialéctica que esgrime Calicles en el Gorgias platónico, pero indispensable -en rigor, irremediable- en el ejercicio de la política auténtica. Y mientras la humanidad espera que la Historia se realice, los políticos genuinos, al igual que los artistas genuinos, se estarían infiltrando en la farsa de los parlamentos democráticos, tal y como se tratase de centros de arte contemporáneos, institucionales y anti-institucionales a la vez. En virtud de los precedentes, no parece tan intempestivo que Pardo califique el fenómeno con el nombre de "totalitarismo líquido" (p. 269).

Cabe recalcar que, a lo largo de este recorrido, Pardo condensa las derivas revolucionarias, tanto políticas como artísticas, en clave de arremetida contra la "autonomía" de estos campos, debido a la manifiesta erosión institucional que implican. Pero quizá no sería equivocado entender, por el contrario, estos asaltos como el fruto último del anhelo por aquilatar esa autonomía (como autoreferencialidad) que tan solo cristalizaría, ya en la entera estetización, ya en la total politización de la vida humana. Un ímpetu a la que no son insensibles las ciencias naturales ("todo es química", "todo es física", "todo es biología", etc.) y resultan tanto más comprensibles de las disciplinas humanas, huérfanas de sentido. Tarea de la filosofía sería sofrenar, más que alentar tales tentaciones.

Por último, el análisis de las últimas décadas de la historia política española atraviesa intermitentemente los "estudios" de Pardo, las cuales ilustrarían por analogía el paso del estado de naturaleza (dictadura) al estado civil (constitucional), transición mediante. Igualmente, existiría aquí una corriente soterrada que desde finales de los años setenta vituperaría la mascarada consensual, esgrimiendo en cambio la autenticidad de su visión teleológica. No obstante, la quiebra del consenso constitucional, prefigurada desde principios del milenio -en coincidencia con el 11S- habría abierto una "ventana de oportunidad" rupturista, gradualmente ensanchada debido a la crisis económica, el $15 \mathrm{M}$ y la subsecuente emergencia de la "nueva política". Una ventana por la que en busca de su destino, según constata Pardo, se han ido colando 
filósofos y politólogos, republicanizando por cierto la "receta populista". El "tercer concepto" de libertad presentado por $\mathrm{Ph}$. Pettit durante el pasado decenio, que de por sí fue irrelevante a efectos democráticos, cobra a esta luz una dimensión insospechada. No en balde -se sostiene- la "libertad negativa" de I. Berlin ya bastaba para apoyar conceptualmente las políticas del Estado de Bienestar (p. 278), (y en este punto siempre ha de recordarse el análisis de J. Gray sobre la defensa berliniana de la "libertad básica de elección" como quicio común a la libertad positiva y negativa -en: Berlin, Harper Collins, Londres, 1995). Sea como fuere, y he aquí quizá la justificación y el homenaje personal del autor a las humanidades, de resultas de tal proceso se ha dejado a merced de una "realidad sólida" la suerte institucional de sus facultades. Y de ahí por fin la amarga sospecha que pende tras la lectura del libro, en torno a los beneficiarios últimos del tránsito experimentado que, por decirlo con R. Cotarelo, va "del Estado de bienestar al Estado del malestar".

José Andrés Fernández Leost Fundación Carolina Universidad Complutense de Madrid 
